\title{
COMPARISON OF METHODS FOR ETHYLHEXYL 4-METHOXYCINNAMATE ACID ESTER OXIDATION IN WATER MEDIUM
}

\author{
Waldemar Studziński' ${ }^{1}$ Alicja Gackowska' \\ 1 Faculty of Chemical Technology and Engineering, University of Technology and Life Science, Seminaryjna 3, \\ 85-326 Bydgoszcz, Poland e-mail: waldemar.studzinski@utp.edu.pl; alicja.gackowska@utp.edu.pl
}

Received: 2017.04.10 Accepted: 2017.05.31 Published: 2017.07.01

\begin{abstract}
The aim of the studies was to compare an impact of oxidizing agents on degradation of ethylhexyl 4-methoxycinnamate acid (EHMC). The oxidation reaction was carried out in the presence of sodium hypochlorite, hydrogen peroxide and ozone with/without UV radiation. EHMC degradation and the analysis of products were performed using gas chromatograph coupled with a mass spectrometry detector. The most effective method of EHMC degradation turned out to be ozonation with participation of UV radiation. In this system, degradation proceeded most quickly and generated a small amount of by-products (2-propyl-1-pentanol; 4-metoxybenzaldehyde and Z-EHMC). Under the influence of sodium hypochlorite, numerous chloroorganic products were formed, which can cause secondary contamination of water. Application of appropriate oxidation processes can contribute to degradation of micropollutants and thus to improvement of water quality.
\end{abstract}

Keywords: EHMC, oxidation, by-products, GC-MS

\section{INTRODUCTION}

In order to protect the skin against radiation, the chemical UV-filters are added to personal care products. The derivatives of cinnamic, salicylic, p-aminobenzoic acids, camphor and also benzophenones are applied as organic UV filters. The compounds that protect against UV radiation are detected in water matrices at the levels from several $\mu \mathrm{g} / \mathrm{m}^{3}$ to even several $\mathrm{mg} / \mathrm{m}^{3}$ [Fent et al. 2008]. They penetrate into environment as a result of the skin rinsing while bathing in a river, lake and sea [Pierogrande et al. 2007]. Their another source are waste waters from households and cosmetic industry [Giokas et al. 2007].

Due to their rapid spread, accumulation in living organisms, lack of permanent monitoring and so far unknown effects on environment, these pollutants are considered as emerging contaminations (ECs) [Gomez et al. 2012]. Commonly used UV filter is 2-ethylhexyl-4-methoxycinnamate (EHMC). In order to know the transformations which can undergo in water medium, the studies on the impact of various environmental factors on its behaviour were carried out. It has been shown that in presence of UV radiation, EHMC undergoes photoisomerization changing form from trans to cis [Hanson et al. 2015; Pattanaargson \& Limphong 2001; Vione et al. 2015]. In turn, in the presence of oxidizing agents there is a risk of oxidation and by-products formation. Studies carried out under the controlled conditions in the presence of sodium hypochlorite i.e. agent used for disinfection of swimming pool waters, have shown that EHMC formed chloroorganic products [Negreira et al. 2008; Nakajima et al. 2009; Gackowska et al. 2016]. The sunscreen agents in environment undergo degradation but products of their transformations can be even more dangerous for environment than UV filters themselves [Gackowska et al. 2016]. Moreover, EHMC accumulates in aquatic biota of different trophic levels with concentrations of up to $340 \mathrm{ng} / \mathrm{g}$ lipids in cormorants [Fent et al., 2008]. EHMC is known as endocrine disrupting compound that cause adverse effects on human and wildlife. On this basis, the Commission (EU) 2015/495 placed EHMC on the list of 17 substances subjected to 
monitoring (Directive of European Parliament and Council 2008/105/WE).

The present state of surface water is alarming, not only in Poland but also worldwide [Bartkowska 2014]. Some countries suffer from lack of water, other bother about a state of its quality [Dąbrowska et al. 2017]. That is why more and more often, the treated wastewaters are used for irrigation of fields [Michael-Kordatou et al. 2015]. Ramos [2015] has shown that the conventional treatment methods are insufficient to eliminate chemical UV filters. It was proved by identification of EHMC, among others, in treated wastewater at the level of 120-849 ng/L [Ekpeghere et al. 2016]. Therefore, there is a need for application of additional processes allowing for elimination of these contaminations. The solution can be advanced oxidation processes AOPs employing oxidizing agents such as hydrogen peroxide or ozone in the systems with UV radiation. These systems were applied for the removal of aniline derivatives [Buthiyappan et al. 2015], macromolecular dyes [Chatha et al. 2016; Sarayu et al. 2007] and phenolic derivatives [Ugurlu et al. 2011]. Hydrogen peroxide or ozone, as a source of hydroxyl radicals, can significantly accelerate the degradation process of EHMC.

The aim of the study was to compare the methods for 2-ethylhexyl 4-methoxycinnamate acid ester degradation in water matrix. The impact of oxidizing agents on the stability of EHMC was tested. The qualitative analysis of the products formed was performed. Sodium hypochlorite, hydrogen peroxide and ozone with/without UV radiation were selected as oxidizing agents.

\section{MATERIALS AND METHODS}

\section{Materials}

All chemicals were purchased from commercial suppliers and used without purification. 2-ethylhexyl 4-methoxycinnamate (E-EHMC, CAS: 5466-77-3) was obtained from Sigma-Aldrich (USA). Sodium hypochlorite $\mathrm{NaOCl}$ with a nominal free chlorine content of $100 \mathrm{~g} / \mathrm{L}$ and $\mathrm{H}_{2} \mathrm{O}_{2}(30 \%)$ were obtained from POCh (Poland). Ozone gas was produced using an ozone generator DRP-30,7 VW (Poland), the flow $4 \mu \mathrm{l} / \mathrm{min}$.

\section{Reaction conditions}

Stock solution $(0.35 \mathrm{mM})$ E-EHMC were prepared in deionized water. In a first step, $0.1 \mathrm{~g}$ of E-EHMC were diluting in $1 \mathrm{ml}$ of methanol in order to improve EHMC solubility. So prepared solution was introduced into $1000 \mathrm{ml}$ of deionized water. Then, oxidizing agents were added and the reaction mixtures, having compositions given in Table 1, were obtained. The effect of UV irradiation was examined with the use of photoreactor equipped with a Heraeus, TQ $150 \mathrm{~W}$ medium pressure mercury lamp (200-600 nm), magnetic stirrer $(200 \mathrm{rpm})$. The temperature in the reactor was ranged from 22 to $25{ }^{\circ} \mathrm{C}$. The reaction was performed by maximum $5 \mathrm{~h}$.

At 30 min intervals, the reaction mixture samples $(100 \mathrm{~mL})$ were extracted for $10 \mathrm{~min}$ by dichloromethane $(20 \mathrm{~mL})$. Then, so-prepared extracts were dried with anhydrous sodium sulfate. After the extract was concentrated by rotary evaporation to a volume of $1 \mathrm{~cm}^{3}$ the OMC transformation products were detected with the use of 5890 HEWLETT PACKARD gas chromatographer equipped with a MS detector and the ZB-5MS column $(0.25 \mathrm{~mm} \times 30 \mathrm{~m} \times 0.25 \mu \mathrm{m})$. The following chromatographic conditions were applied: sample volume $1 \mu \mathrm{L}$, helium carrier gas, injector temperature $250{ }^{\circ} \mathrm{C}$, oven temperature program from 80 to $260{ }^{\circ} \mathrm{C}$ at $10{ }^{\circ} \mathrm{C} / \mathrm{min}$, from 260 to $300{ }^{\circ} \mathrm{C}$ at $5^{\circ} \mathrm{C} / \mathrm{min}$.

\section{RESULTS AND DISCUSSION}

On the basis of our studies, it was found that E-EHMC is unstable in the presence of oxidizing agents (Fig. 1). It was observed that after 3 hours of reaction, without UV radiation, degradation of E-EHMC proceeded in $20 \%$ in the presence of hydrogen dioxide and in $35 \%$ in the presence of ozone. The most effective degradation of E-EHMC occurred in the presence of sodium hypochlorite. E-EHMC degradation is accelerated, when the oxidation process is additionally aided by UV radiation. The most effective solution was the use of ozone with UV radiation; photodegradation in this system lasted 50 minutes. However, in the case of $\mathrm{NaOCl} / \mathrm{UV}$ and $\mathrm{H}_{2} \mathrm{O}_{2} / \mathrm{UV}$ decomposition proceeded with a similar rate and after 1.5 hours, the loss of sunscreen was about $60 \%$ and after 3 hours E-EHMC was practically completely degraded. 
Table 1. The reaction conditions and substrate proportions used in this study

\begin{tabular}{|c|c|c|c|c|c|}
\hline Reagents & $\mathrm{OMC}[\mathrm{mM}]$ & $\mathrm{H}_{2} \mathrm{O}_{2}[\mathrm{mM}]$ & $\mathrm{NaOCl}[\mathrm{mM}]$ & $\mathrm{O}_{3}[\mathrm{mM}]$ & UV $[\mathrm{W}]$ \\
\hline $\mathrm{E}-\mathrm{EHMC} / \mathrm{UV}$ & 0.35 & - & - & - & 150 \\
\hline $\mathrm{E}-\mathrm{EHMC} / \mathrm{NaOCl}$ & 0.35 & - & 10 & - & - \\
\hline $\mathrm{E}-\mathrm{EHMC} / \mathrm{NaOCI} / \mathrm{UV}$ & 0.35 & - & 10 & - & 150 \\
\hline $\mathrm{E}-\mathrm{EHMC} / \mathrm{H}_{2} \mathrm{O}_{2}$ & 0.35 & 10 & - & - & 150 \\
\hline $\mathrm{E}-\mathrm{EHMC} / \mathrm{H}_{2} \mathrm{O}_{2} / \mathrm{UV}$ & 0.35 & 10 & - & - & - \\
\hline $\mathrm{E}-\mathrm{EHMC} / \mathrm{O}_{3}$ & 0.35 & - & - & 10 & 150 \\
\hline $\mathrm{E}-\mathrm{EHMC} / \mathrm{O}_{3} / \mathrm{UV}$ & 0.35 & - & - & 10 & \\
\hline
\end{tabular}

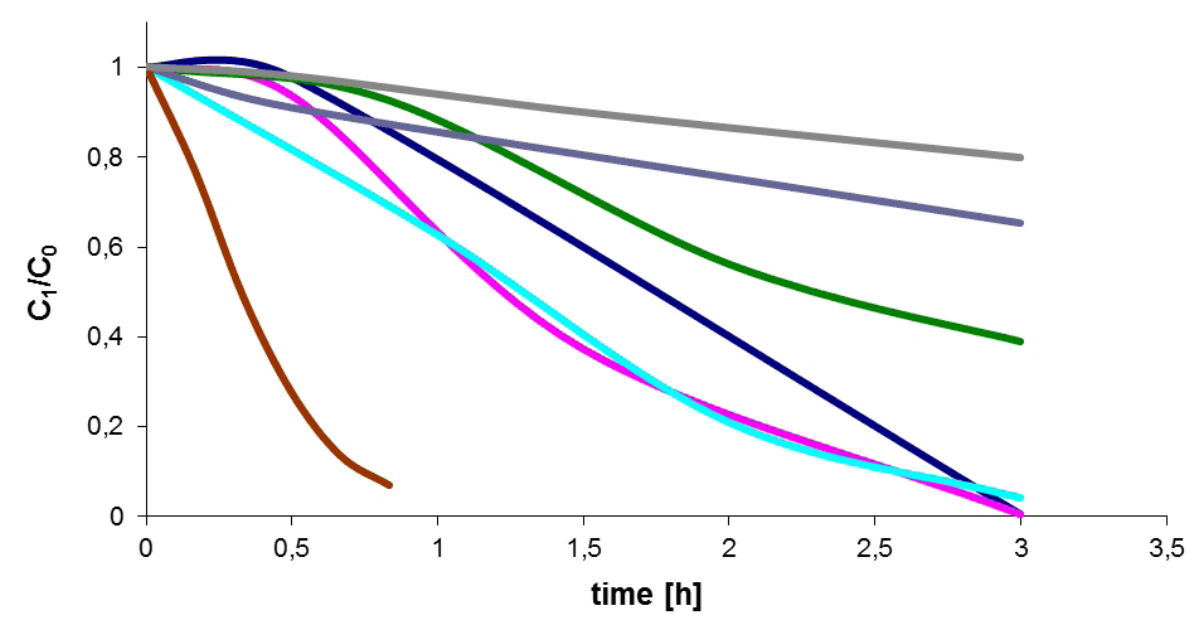

Fig. 1. Degradation of E-EHMC under the influence of the systems tested as a function of time:

- E-EHMC/UV; - E-EHMC/NaOCl; - E-EHMC/NaOCl/UV; - E-EHMC/ $\mathrm{H}_{2} \mathrm{O}_{2}$; - E-EHMC/ $\mathrm{H}_{2} \mathrm{O}_{2} / \mathrm{UV} ;-\mathrm{E}-\mathrm{EHMC} / \mathrm{O}_{3} ;-\mathrm{E}-\mathrm{EHMC} / \mathrm{O}_{3} / \mathrm{UV}$

When selecting a method for E-EHMC removal from water matrix, the degradation by-products were also taken into consideration. Sspecial attention was paid to the compounds (4-metoxybenzaldehyde; 2-propyl-1-pentanol; 2-ethylhexyl alcohol), which in the presence of disinfectant $(\mathrm{NaOCl})$ could be the source of THM and benzene chloroderivatives, which demonstrate toxic properties. It allows to estimate whether the secondary contamination of water can occur during the process of E-EHMC oxidation. The products of E-EHMC transformations under the influence of various agents are presented in Figure 2.

Identification of products formed during E-EHMC oxidation in the presence of sodium hypochlorite was described in our previous paper [Gackowska et al. 2016]. In the reaction products, besides mono and EHMC dichloroderivetives, the following compounds were identified: 1-Chloro4-methoxybenzene, 1.3-Dichloro-2-methoxybenzene, 2-Ethylhexyl chloroacetate, 3-Chloro4-methoxybenzaldehyde, Z-EHMC, 1EHMCCl and 2EHMCCl. While applying $\mathrm{NaOCl} / \mathrm{UV}$ system after 180 min of reaction, a considerably low- er amount of by-products was observed. The metabolites such as 2-Ethylhexyl alcohol, Z-EHMC, $1 \mathrm{EHMCCl}$ and $2 \mathrm{EHMCCl}$ were identified in post-reaction mixture. Due to the fact that additive action of UV radiation results in formation of lower quantities of chloroorganic products, it was decided to prolong time of the solution exposure by two hours. After 5 hours of reaction in the system $\mathrm{EHMC} / \mathrm{NaOCl} / \mathrm{UV}$ only one metabolite Z-EHMC was identified (Fig. 3).

Studies on the effect of sodium hypochlorite on EHMC oxidation were also carried out by Nakajima et al. [2009] and Santos et al. [2013], who identified only mono and dichloroderivatives of EHMC among the reaction products. According to Nakajima et al. [2009], in the first stage of chlorination the mutagenic products are formed which, because of their poor stability, at a later time can undergo transformations to less mutagenic compounds. Our studies suggest that UV radiation accelerates transformation of mono and dichliroderivatives of EHMC. In turn, the products of these transformations which are undesirable in purification and/or treat- 


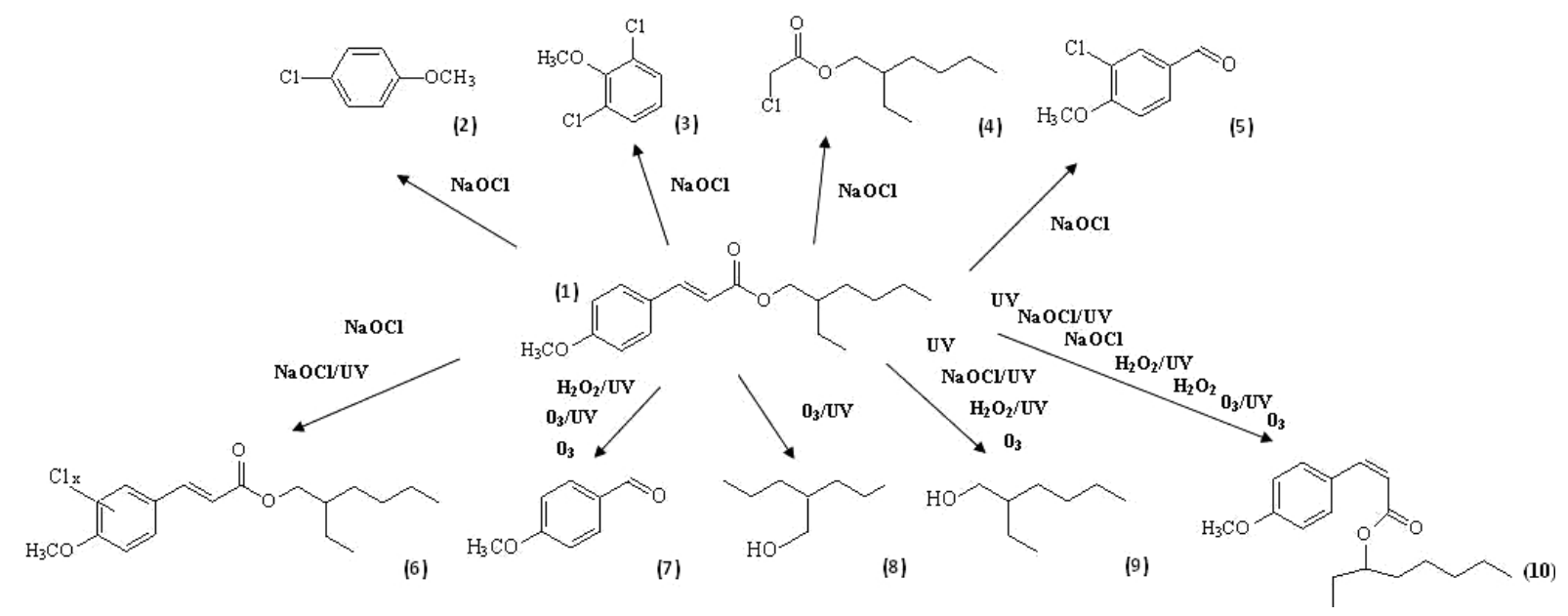

Fig. 2. Transformations of E-EHMC under the influence of oxidizing agents in presence of UV radiation: (1) EEHMC; (2) 1-Chloro-4-methoxybenzene; (3) 1.3-Dichloro-2-methoxybenzene; (4) 2-Ethylhexyl chloroacetate; (5) 3-Chloro-4-methoxybenzaldehyde; (6) EHMCCl ; (7) 4-metoxybenzaldehyde; (8) 2-propyl-1-pentanol; (9)

2-Ethylhexyl alcohol; (10) Z-EHMC

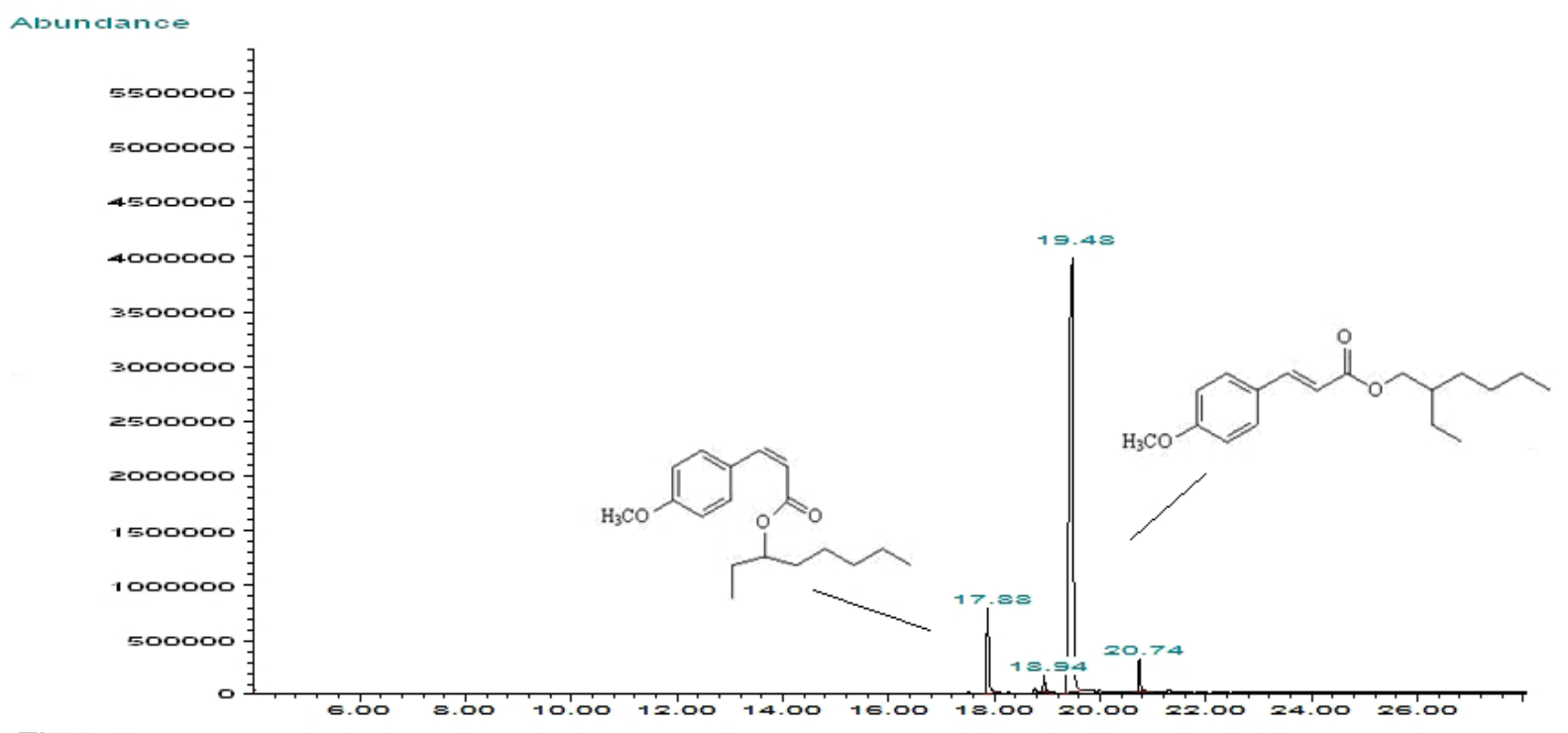

Fig. 3. Chromatogram of E-EHMC/NaOCl/UV system after $5 \mathrm{~h}$

ment of water, can also undergo decomposition at suitably long exposition.

In the case of E-EHMC with hydrogen peroxide, the reaction proceeds very slowly. In reaction products only isomer Z-EHMC was identified. Exposure to UV radiation in this system resulted in degradation of E-EHMC. The following compounds were identified among reaction products: 2-ethylhexyl alcohol, 4-metoxybenzaldehyde and Z-EHMC [Gackowska et al. 2016].

The most effective and generating the smallest amount of products method for removing EEHMC from water matrix is ozonation. In the system $\mathrm{EHMC} / \mathrm{O}_{3}$ the following reaction products were identified: 2-ethylhexyl alcohol, 4-metoxybenzaldehyde and Z-EHMC (Fig. 4a). It is known that ozone is a powerful oxidant capable of oxidative degradation of many trace organic pollutants, readily available and soluble in water. Under real conditions, its effectiveness can be considerably lower because it acts non-selectively and competing processes with other contaminants can occur. It was confirmed by Li et al. [2007], who applied ozonation process for elimination of sunscreens from wastewater. They showed that the effectiveness of EHMC elimination in real conditions was lower than the expected value. Researchers do not specify what products are formed in the 

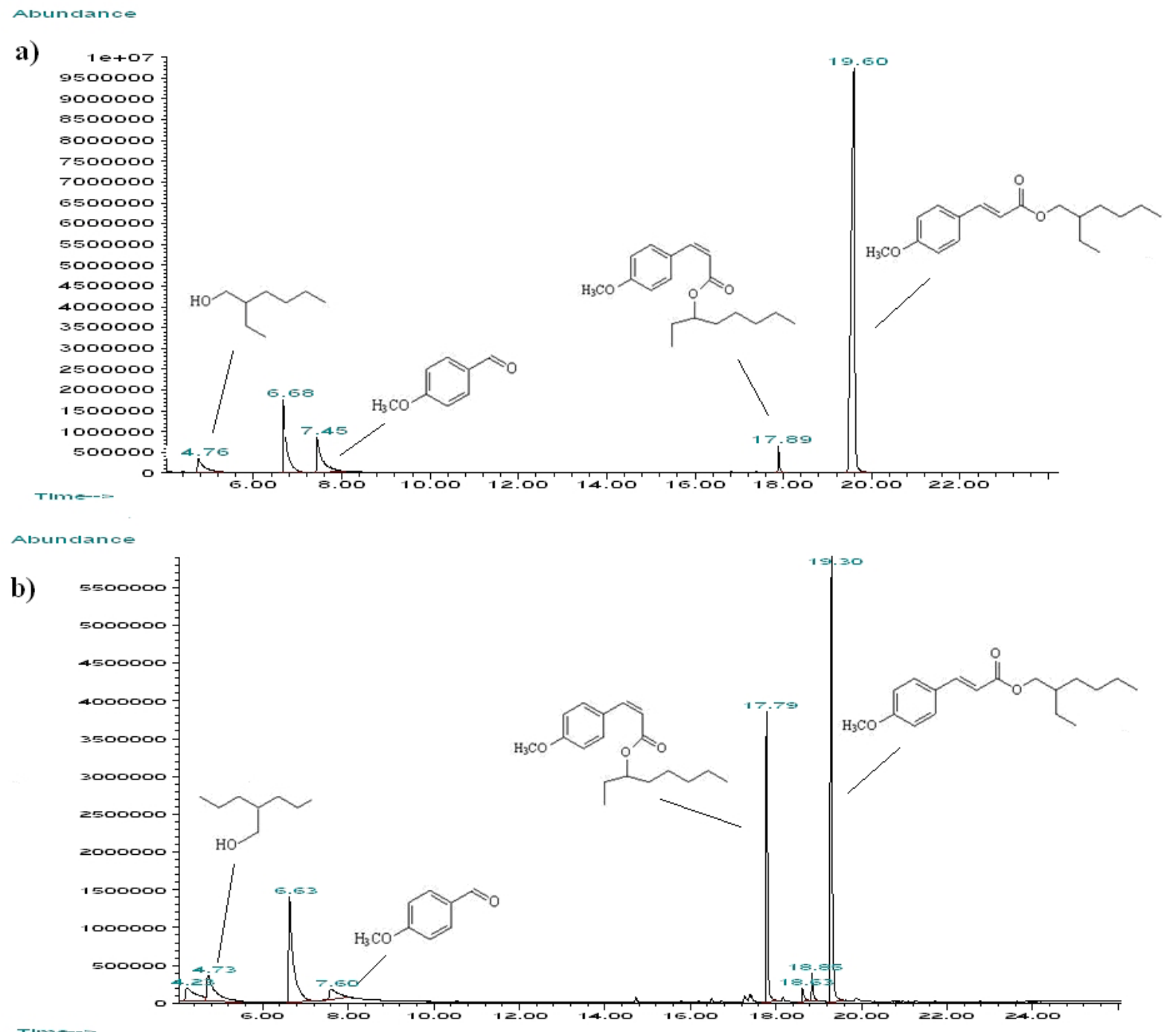

Fig. 4. Chromatogram of systems: a) E-EHMC/O $\mathrm{O}_{3}$; b) E-EHMC/O ${ }_{3} / \mathrm{UV}$

process of EHMC ozonation. The effectiveness of the ozonation increased when the system EHMC/ $\mathrm{O}_{3}$ was subjected to UV radiation. The following compounds were identified in reaction products: 2-propyl-1-pentanol; 4-metoxybenzaldehyde and Z-EHMC (Fig. 4b).

While selecting the effective oxidizing agents we should also take into consideration the impact of metabolites on the environment. Jităreanu et al. [2011] showed that lipophilic derivatives of cinnamic acid demonstrated high phytotoxic potential. In turn, chlorobenzene derivatives, which according United States Environmental Protection Agency are characterized by high toxicity to priority environment pollutants $[\mathrm{He}$ et al. 2000]. It should be emphasized that in each system under the study, the degradation products are formed in trace amounts and therefore, the evaluation of their effect on environment is more difficult. However, according to Kondo et al. [2005], the mixture of chlororganic products can totally have considerably higher indicator of biodegradation than the substrate.

\section{CONCLUSIONS}

The methods of E-EHMC elimination from the water environment were compared. It was found that E-EHMC underwent the processes of oxidation, chlorination and photodegradation resulting in the formation of by-products that did not have the same toxicological profiles as the parent compound. The development of effective methods for removing organic micropollutants can contribute to the improvement of water quality.

The advanced oxidixing processes are effective for elimination of E-EHMC from the water 
matrix. However, it should be noted that in each variant the metabolites are formed and it can lead to secondary contamination of water. The most effective solution was while applying ozone and UV irradiation. The less by-products were formed in this process. E-EHMC oxidation with sodium hypochlorite generates chloroorganic products which can be even more toxic than the substrate. Application of processes involving UV irradiation significantly reduces time of E-EHMC degradation and contributes to degradation of chloroorganic products.

In summary, taking into account the need to develop the methods for removing micropollutants from water as well as a relative lack of data concerning the impact of products of E-EHMC transformations on water environment, the attention should be focused on research taking both these aspects into consideration.

\section{REFERENCES}

1. Bartkowska I. 2014. Dynamics of water consumption changes in a tourist resort. Journal of Ecological Engineering, 15, 46-54.

2. Buthiyappan A., Aziz A., Raman A., Daud W. 2015. Degradation performance and cost implication of UV-integrated advanced oxidation processes for wastewater treatments. Reviews in Chemical Engineering, 3, 263-302.

3. Chatha, S.H., Ali S., Kiran S., Gulzar T., Kamal S.H., Ghaffar A., Chatha M.N. 2016. Comparative study on decolorisation and mineralization of synthetic and real textile effluents using advanced oxidation processes. Oxidation Communications , 39 1604-1614.

4. Dąbrowska J., Bawiec A., Pawęska K., Kamińska J., Stodolak R. 2017. Assessing the Impact of Wastewater Effluent Diversion on Water Quality. Polish Journal of Environmental Studies, 26, 9-16.

5. Directive of European Parliament and Council 2008/105/WE.

6. Ekpeghere K.I., Kim U.J., O S.H., Kim H.Y., Oh J.E. 2016. Distribution and seasonal occurrence of UV filters in rivers and wastewater treatment plants in Korea. Science of the Total Environment, 542, 121-128.

7. Fent L., Kunzac P. Y., Gomezd E. 2008. UV Filters in the Aquatic Environment Induce Hormonal Effects and Affect Fertility and Reproduction in Fish. Chimia, 62, 368-370.

8. Gackowska A., Przybyłek M., Studziński W., Gaca J. 2016. Formation of chlorinated breakdown products during degradation of sunscreen agent, 2-eth- ylhexyl-4-methoxycinnamate in the presence of sodium hypochlorite. Environ Sci Pollut Res, 23, 1886-1897.

9. Giokas D.L., Salvador A., Chisvert A. 2007. UV filters: From sunscreens to human body and the environment. Trends in Analytical Chemistry, 5(26), 360-374.

10. Gomez E., Bachelot M., Boillot C., Munaron D., Chiron S., Casellas C., Fenet H. 2012. Bioconcentration of two pharmaceuticals (benzodiazepines) and two personal care products (UV filters) in marine mussels (Mytilus galloprovincialis) under controlled laboratory conditions. Environ Sci Pollut Res, 19, 2561-2569.

11. Hanson K.M., Narayanan S., Nichols V.M., Barden ChJ. 2015. Photochemical degradation of the UV filter octyl methoxycinnamate in solution and in aggregates. Photochem Photobiol Sci, 14, 1607-1616.

12. He Y., Wang Y., Lee H.K. 2000. Tracę analysis of ten chlorinated benzenes in water by headspace solid-phase microextraction. J. Chromatogr. A, 874, 149-154.

13. Jităreanu A., Tătărîngă G., Zbancioc A.M., Stănescu U. 2011. Toxicity of Some Cinnamic Acid Derivatives to Common Bean (Phaseolus vulgaris). Notulae Botanicae Horti Agrobotanici, 39 (2), 130-134.

14. Kondo T., Yamamoto H., Tatarazako N., Kawabe K., Koshio M., Hirai N., Morita M. 2005. Bioconcentration factor of relatively low concentrations of chlorophenols in Japanese medaka. Chemosphere, 61(9), 1299-1304.

15. Li W.H., Ma Y.M., Guo C.S., Hu W., Liu K.M., Wang Y.Q., Zhu T. 2007. Occurrence and behavior of four ofthe most used sunscreen UV filters in a wastewater reclamation plant. Water Research, 41(15), 3506-3512.

16. Michael-Kordatou I., Michael C., Duan X., He X., Dionysiou D.D., Mills M.A., Fatta-Kassinos D. 2015. Dissolved effluent organic matter: Characteristics and potential implications in wastewater treatment and reuse applications. Water Res, 77, 213-248.

17. Nakajima M., Kawakami T., Niino T., Takahashi Y., Onodera S. 2009. Aquatic fate of sunscreen agents octyl-4-methoxycinnamate and octyl-4-dimethylaminobenzoate in model swimming pools and the mutagenic assays of their chlorination byproducts. J Health Sci, 55, 363-372.

18. Negreira N., Canosa P., Rodríguez I., Ramil M., Rubí E., Cela R. 2008. Study of some UV filters stability in chlorinated water and identification of halogenated by-products by gas chromatography-mass spectrometry. J Chromatogr A, 1178 (1-2), 206-214.

19. Pattanaargson S, Limphong P. 2001. Stability of octyl methoxycinnamate and identification of its 
photo-degradation product. Int J Cosmetic Sci, 23, 153-160.

20. Pierogrande M. Ch., Basagila G. 2007. GC-MS analityical methods for the determination of personal-care products in water matrices. Trends in Analytical Chemistry, 26, 1086-1094.

21. Ramos S., Homem V., Alves A., Santos L. 2015. Advances in analytical methods and occurrence of organic UV-Filters in the environment. Science of the Total Environment, 526, 278-311.

22. Santos A.J.M., Crista D.M.A., Miranda M.S., Almeida I.F., Silva J.P., Costa P.C., Amaral M.H., Lobão P.A.L., Sousa Lobo J.M., da Silva J.C.G.E. 2013. Degradation of UV filters 2-ethylhexyl-4methoxycinnamate and 4-tert-butyl-4- methoxydibenzoylmethane in chlorinated water. Environ Chem,
$10(2), 127-134$.

23. Sarayu K., Swaminathan K., Sandhya S. 2007. Assessment of degradation of eight commercial reactive azo dyes individually and in mixture in aqueous solution by ozonation. Dyes Pigments, 75, 362-368.

24. Ugurlu M., Karaoglu M.H. 2011. TiO supported on sepiolite: Preparation, structural and thermal characterization and catalytic behaviour in photocatalytic treatment of phenol and lignin from olive mill wastewater. Chem. Eng. J., 166, 859-867.

25. Vione D., Calza P., Galli F., Fabbri D., Santoro V., Medana C. 2015. The role of direct photolysis and indirct photochemistry in the environmental fate of ethylhexyl methoxy cinnamate (EHMC) in surface waters. Sci Total Environ, 537, 58-68. 